\title{
JOINT DEVELOPMENT OF A FOURTH GENERATION SINGLE CRYSTAL SUPERALLOY
}

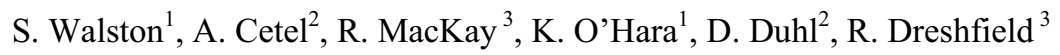 \\ 1. GE Aircraft Engines, Cincinnati, OH and Lynn, MA , 2. Pratt \& Whitney, East Hartford, CT, \\ 3. NASA Glenn Research Center, Cleveland, $\mathrm{OH}$
}

Keywords: single crystal superalloy, alloy development, ruthenium, TCP, SRZ, creep rupture

\begin{abstract}
A new, fourth generation, single crystal superalloy has been jointly developed by GE Aircraft Engines, Pratt \& Whitney and NASA. The focus of the effort was to develop a turbine airfoil alloy with long-term durability for use in the High Speed Civil Transport. In order to achieve adequate long-time strength improvements at moderate temperatures and retain good microstructural stability, it was necessary to make significant composition changes from $2^{\text {nd }}$ and $3^{\text {rd }}$ generation single crystal superalloys. These included lower chromium levels, higher cobalt and rhenium levels and the inclusion of a new alloying element, ruthenium. It was found that higher Co levels were beneficial to reducing both TCP precipitation and SRZ formation. Ruthenium caused the refractory elements to partition more strongly to the $\gamma$ ' phase, which resulted in better overall alloy stability. The final alloy, EPM-102, had significant creep rupture and fatigue improvements over the baseline production alloys and had acceptable microstructural stability. The alloy is currently being engine tested and evaluated for advanced engine applications.
\end{abstract}

\section{Introduction}

This alloy development effort was conducted under the Enabling Propulsion Materials (EPM) program of the High Speed Civil Transport (HSCT) project sponsored by NASA. In contrast to subsonic engines, which accumulate hundreds of hot hours, the accumulated hot time of an HSCT engine was projected to be many thousands of hours and as a result, the alloy property goals centered around long-time, moderate $\left(925-1050^{\circ} \mathrm{C}\right)$ temperature performance. Specifically, the alloy goals were to attain a $42^{\circ} \mathrm{C}$ benefit in creep rupture strength over the $2^{\text {nd }}$ generation production turbine blade alloys, PWA 1484 and René N5, which were current at the program initiation in 1994. In addition, the alloy goals were to have sufficient microstructural stability to avoid degradation of long-time properties and acceptable environmental resistance and castability.

Early studies by GEAE and P\&W, as well as patent and literature searches, indicated that obtaining a balance of properties would be difficult. The occurrence of Secondary Reaction Zone (SRZ) in $3^{\text {rd }}$ generation alloys was a newly discovered instability at thiat time [1] and needed to be addressed. It was known that increasing the creep strength would require higher levels of refractory elements than that contained in $3^{\text {rd }}$ generation alloys, which could lead to unacceptable levels of topologically close packed (TCP) phase formation. Ideas explored to improve stability included lowering $\mathrm{Cr}$ to $1 \%$ to accommodate higher refractory levels [2], increasing $\mathrm{Co}$ to $20 \%$ and adding $\mathrm{Ru}$ in order to affect the elemental partitioning and thereby improve microstructural stability [3]. As will be shown, $\mathrm{Ru}$ was determined to be a critical element to the success of the alloy development program as it could be added to achieve both improved microstructural stability and increased high temperature creep strength. Subsequent alloy development efforts by others [4-6] have led to similar conclusions on the usefulness of $\mathrm{Ru}$ in $4^{\text {th }}$ generation single crystal superalloys.

\section{Alloy Development Approach}

The HSCT mission cycle was projected to have the highest operating temperatures during the climb and supersonic cruise portion of the mission. This mission imposed unique requirements on the long-time stability and strength of the turbine airfoil alloys and had a strong influence on the alloy development approach and selection of the final alloy.

Several rounds of development alloys were evaluated covering a wide range of compositions. Alloy compositions were derived as a result of various multiple regression analyses of prior alloys, as well as substantial use of neural networks. Typically, the neural networks gave considerably better predictive capability than the best multiple regression model constructed from the same data. The networks were trained using prior GEAE or P\&W alloy data, and then EPM data was included as it became available. Several network node designs were typically used for each property, and the average of these networks was used to give a more robust and generalized prediction for future alloy properties. Each round of alloys was formulated using the design of experiments (DoE) approach. Most rounds were a fractional factorial design that allowed for the determination of individual elemental effects and elemental interactions.

Candidate alloy properties were evaluated using single crystal slabs cast at either GEAE, Howmet or PCC. If necessary, trials were conducted to determine the proper solution heat treat cycle 
for each alloy and then a two-step aging heat treatment was utilized. Alloys were typically solution heat treated for 4-6 hours at $1315-1330^{\circ} \mathrm{C}$ depending on composition, and nearly complete solutioning was achieved in most alloys. For each round of alloy screening, there were several evaluations conducted, including:

- Microstructural stability (TCP) after $982^{\circ} \mathrm{C}$ and $1093^{\circ} \mathrm{C}$ exposure (furnace and creep)

- Internal cellular colony and SRZ stability evaluation

- 982 to $1093^{\circ} \mathrm{C}$ stress rupture testing

- $1177^{\circ} \mathrm{C}$ oxidation testing in Mach 1 burner rig

Limited $649^{\circ} \mathrm{C}$ tensile tests, hot corrosion tests and long-time stress rupture testing at 927 and $982^{\circ} \mathrm{C}$ were also used to gauge the alloys against the HSCT goals.

\section{$\underline{\text { Compositional Effects on Microstructural Stability }}$}

The effect of many different elements, including $\mathrm{Cr}, \mathrm{Al}, \mathrm{Co}, \mathrm{W}$, $\mathrm{Re}, \mathrm{Ru}$ and Ta, on the formation of TCP and SRZ was studied through a series of composition DoE's. Table I shows the typical ranges evaluated in some of the early alloy series. In several of these designed experiments, it was shown that higher Co levels reduced TCP phase precipitation after exposure. One example of this is illustrated in Figure 1, showing that Co contents above 15 wt.\% resulted in much lower TCP levels after exposure at $1093^{\circ} \mathrm{C}$ for 1000 hours. This effect was also shown through neural network modeling, as shown in Figure 2. Re and Co both had critical effects on the amount of TCP formation. High levels of Co were shown to be very effective in reducing TCP formation, while high levels of Re promoted TCP phase precipitation.

Table I. Ranges Evaluated in Early Screening Trials, wt.\%.

\begin{tabular}{|c|c|c|c|c|}
\hline Al & Cr & Co & W & Re \\
\hline $5.5-6.0$ & $1.5-4.25$ & $12.5-20$ & $5.25-8.0$ & $5.25-6.5$ \\
\hline
\end{tabular}

Also $2 \%$ Mo and $8 \%$ Ta
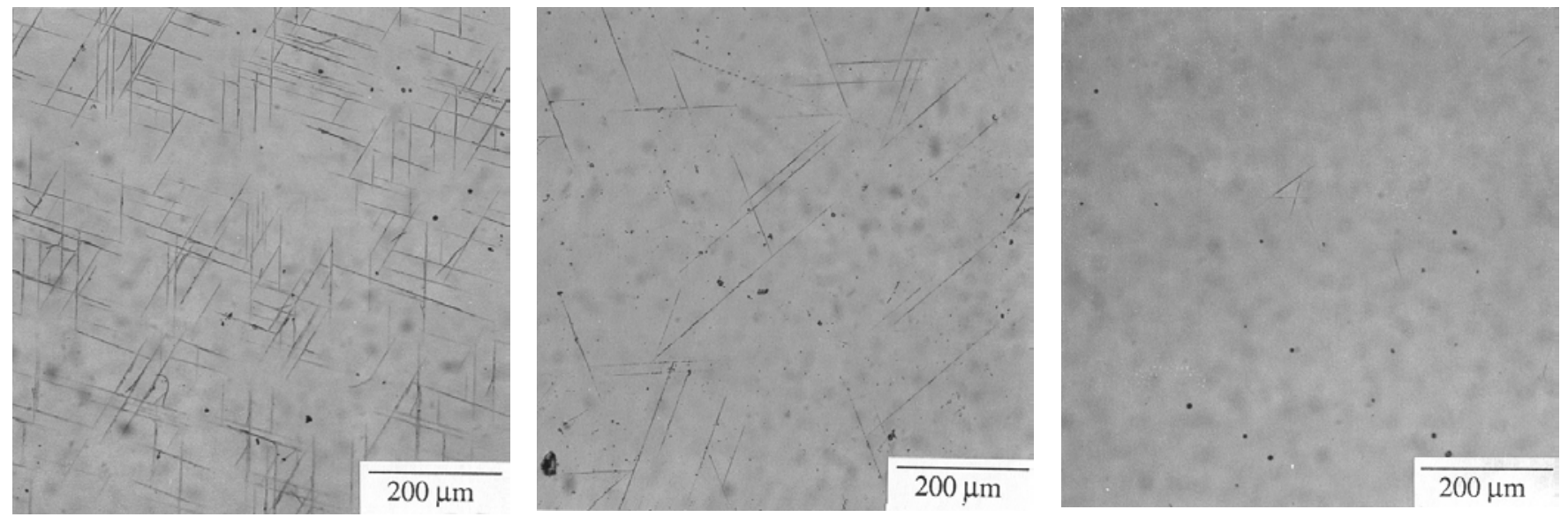

Figure 1. Effect of various Co levels on the amount of TCP precipitation after a $1093^{\circ} \mathrm{C} / 1000 \mathrm{hr}$ exposure.

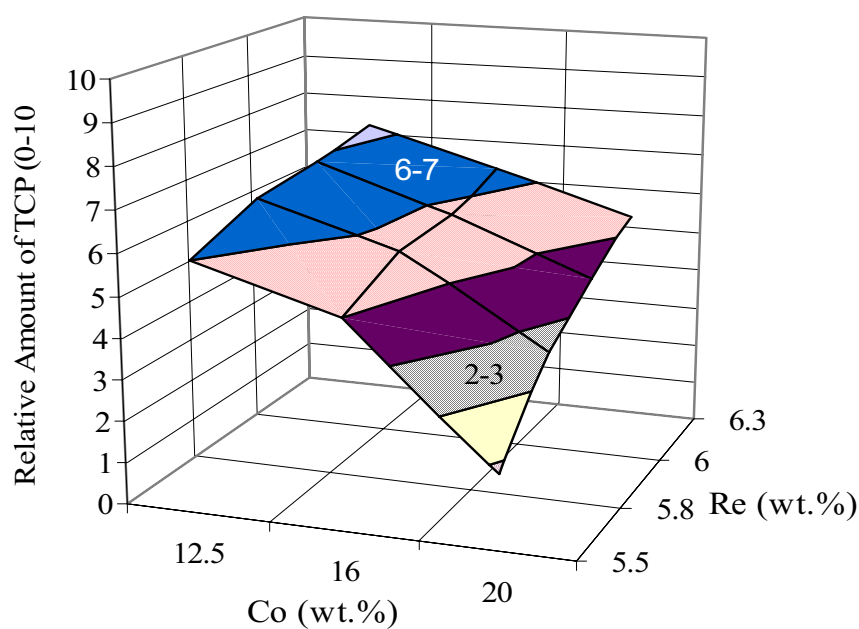

Figure 2. Neural network model prediction of the effect of Co and Re on TCP formation after a $1093^{\circ} \mathrm{C} / 1000 \mathrm{hr}$ exposure. The Co effect correlates well to experimental data in Figure 1.
$\mathrm{Ru}$ was also studied in-depth to determine its effect on TCP stability. Phase extraction studies were conducted on over 60 alloys in which the $\gamma, \gamma^{\prime}$, and TCP phases were separated electrolytically and then chemically analyzed by inductively coupled plasma [7]. These 60 alloys had Ru contents from 0-4.5 $w t \%$, Re from 4.8-7.4 wt $\%$ and Co from 5-25 wt $\%$. The partitioning ratio for each alloying element was calculated by dividing the concentration (in atomic percent) of each element in the $\gamma$ phase by its concentration in the $\gamma^{\prime}$ phase. Figure 3 shows an example where the addition of $1.5 \mathrm{wt} . \% \mathrm{Ru}$ to two alloys caused more Al to partition to the $\gamma$ phase and more of the refractory elements $\mathrm{W}, \mathrm{Re}, \mathrm{Cr}$, and Mo to partition to the $\gamma$ ' phase. In these particular alloys, the compositions in wt $\%$ were $5.5 \mathrm{Al}, 7.9 \mathrm{Ta}, 1.5$ Cr, 20.0 Co and 2.0 Mo. Alloys EPM-13 and 25, contained 7.9 W and 5.5 Re, while EPM-16 and 26 had $8.0 \mathrm{~W}$ and 6.5 Re. In order to show the partitioning effect over larger ranges of $\mathrm{Ru}$ and $\mathrm{Co}$ additions, a neural net analysis was performed based on the actual partitioning data. Figure 4 confirms that the partitioning of Re to the $\gamma$ phase decreased as Ru and/or Co increased. Neural nets 


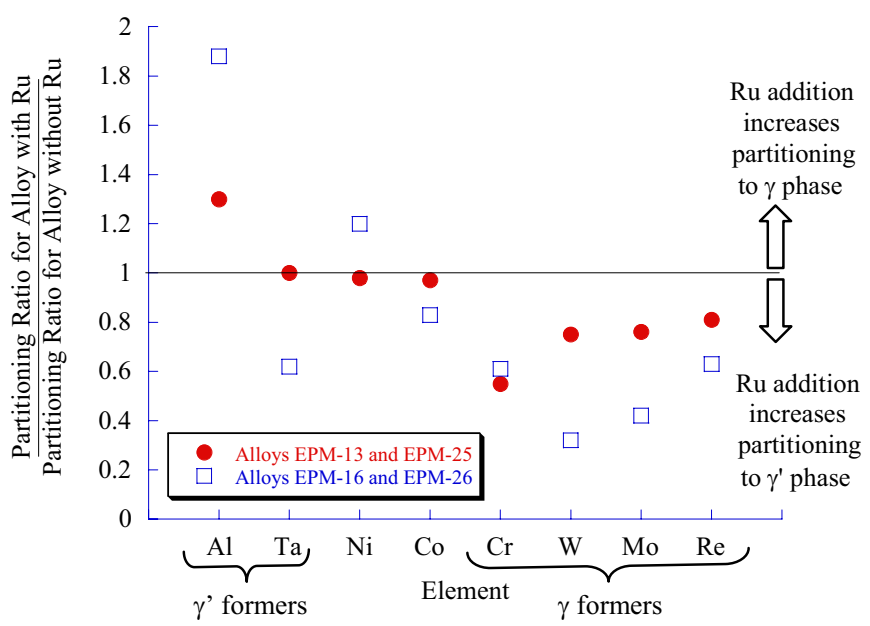

Figure 3. The effect of $\mathrm{Ru}$ additions on the partitioning ratio of various elements. $\mathrm{Ru}$ additions of $1.5 \mathrm{wt} \%$ were made to two different alloys (EPM-13 and 16).

showed similar trends for the $\mathrm{W}$ partitioning coefficient as $\mathrm{Ru}$ and/or Co were increased. Thus, the presence of $\mathrm{Ru}$, as well as the higher levels of $\mathrm{Co}$, caused more of the $\gamma$ formers to partition to the $\gamma$ ' phase. This behavior is the so-called "reverse partitioning effect" of $\mathrm{Ru}$ [3], which helped to improve stability since high concentrations of refractory elements in the $\gamma$ phase trigger the formation of TCP phases. With higher levels of refractory elements in the $\gamma^{\prime}$ phase, susceptibility to TCP precipitation in the $\gamma$ phase was reduced.

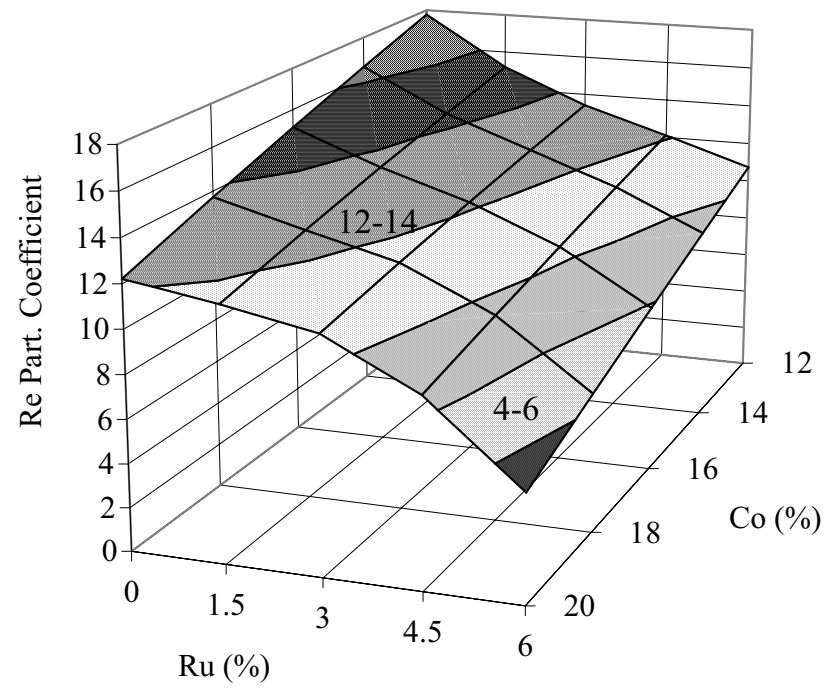

Figure 4. Neural network model prediction of the effect of Ru and $\mathrm{Co}$ additions on the partitioning coefficient of Re. Base alloy is $5.7 \mathrm{Al}, 8 \mathrm{Ta}, 6 \mathrm{~W}, 2 \mathrm{Cr}, 6 \mathrm{Re}$ and $2 \mathrm{Mo}$ in wt.\%.

Controlling and mitigating the potentially detrimental effects of the secondary reaction zone (SRZ) instability was another significant task in this program. All of the alloys evaluated formed at least some amount of SRZ beneath PtAl coatings after exposures at $1093^{\circ} \mathrm{C}$. SRZ was measured around the periphery of a coated specimen, and the amount of surface linear area containing SRZ was quantified and categorized on a scale of 0-10. Neural networks were used to predict elemental effects on SRZ occurrence. Figure 5 shows a neural net model for Re and W effects at two different Ru levels. This analysis showed that high $\mathrm{W}$ and Re can cause a significant increase in SRZ formation and that increasing the Ru content is very effective in suppressing the SRZ formation. This was verified experimentally, and Figure 6 shows the same trend for Re as previously shown in Figure 5, as well as the same beneficial effect of $\mathrm{Ru}$. Because very good experimental confirmation of these and other trends was demonstrated, neural nets were also used to predict several properties and assist with alloy selection. In addition to composition modifications, SRZ formation was controlled by successfully employing various stress relief heat treatments, carburization cycles and other mitigation techniques.

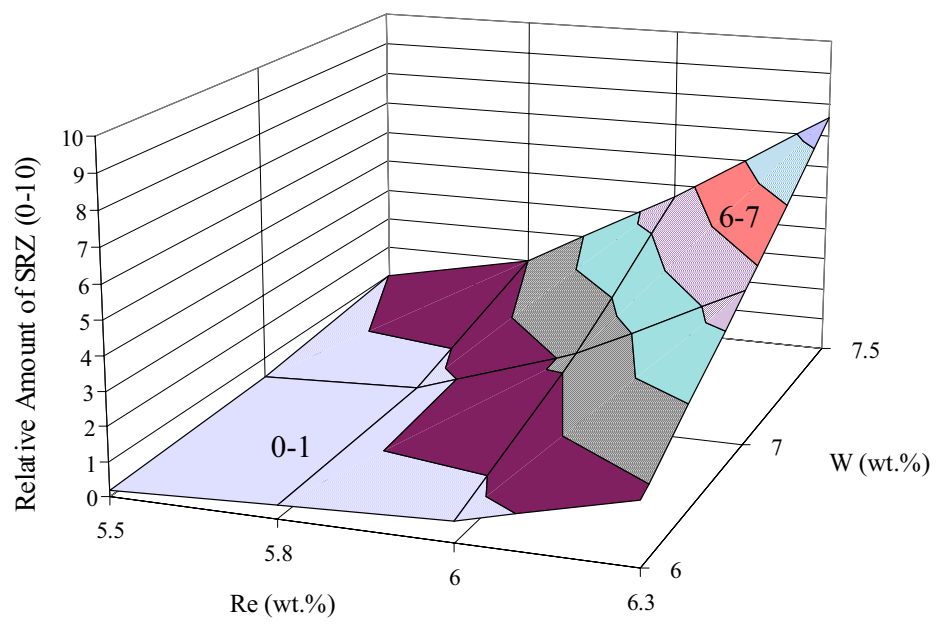

(a) $1.5 \mathrm{wt} . \% \mathrm{Ru}$

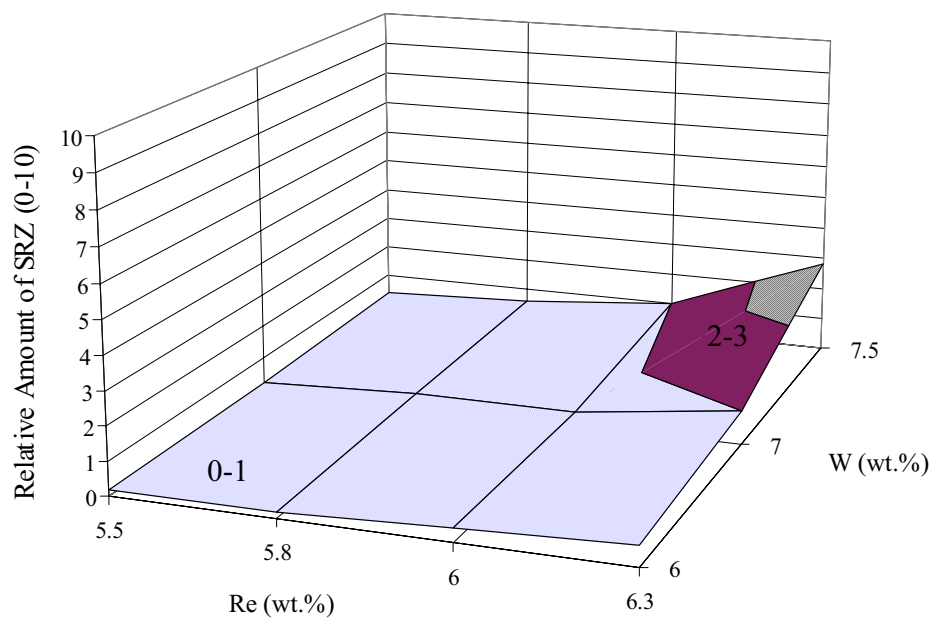

(b) 3.0 wt.\% Ru

Figure 5. Neural network model prediction for the effect of Re and $\mathrm{W}$ on SRZ formation at two different Ru levels. Note that $\mathrm{Ru}$ has a very strong effect on suppressing SRZ formation. 


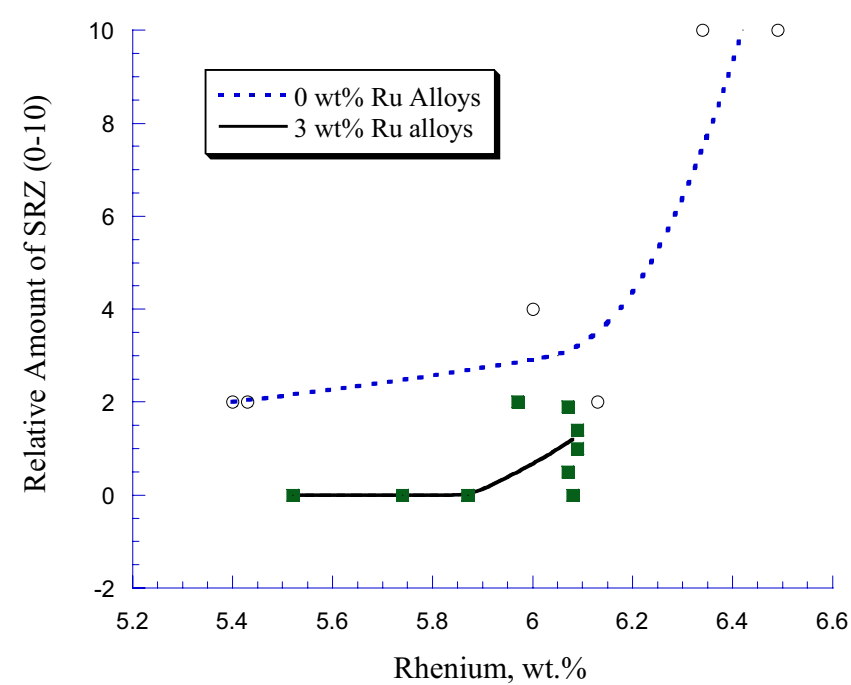

Figure 6. The effect of Re levels on SRZ formation beneath PtAl coatings after $1093^{\circ} \mathrm{C}$ exposure.

\section{Compositional Effects on Oxidation Resistance}

It was known that achieving excellent oxidation resistance in the EPM alloys would be a challenge due to the high refractory content of the alloy. In addition, the effect of $\mathrm{Ru}$ on oxidation behavior was unknown. Figure 7 shows that increasing levels of $\mathrm{Ru}$ did not affect the bare oxidation resistance of a base alloy containing 5.6 wt.\% $\mathrm{Al}$ and $20 \mathrm{wt} . \%$ Co. To help improve the oxidation resistance of this base alloy, the addition of reactive elements was also evaluated. Figure 8 shows that adding Hf, Y and $\mathrm{Ca}$ significantly improved the bare oxidation resistance of an early development alloy. Based on these results, it was shown that it was possible for $4^{\text {th }}$ generation alloys, even with higher refractory contents, to have oxidation resistance comparable to earlier generation alloys.

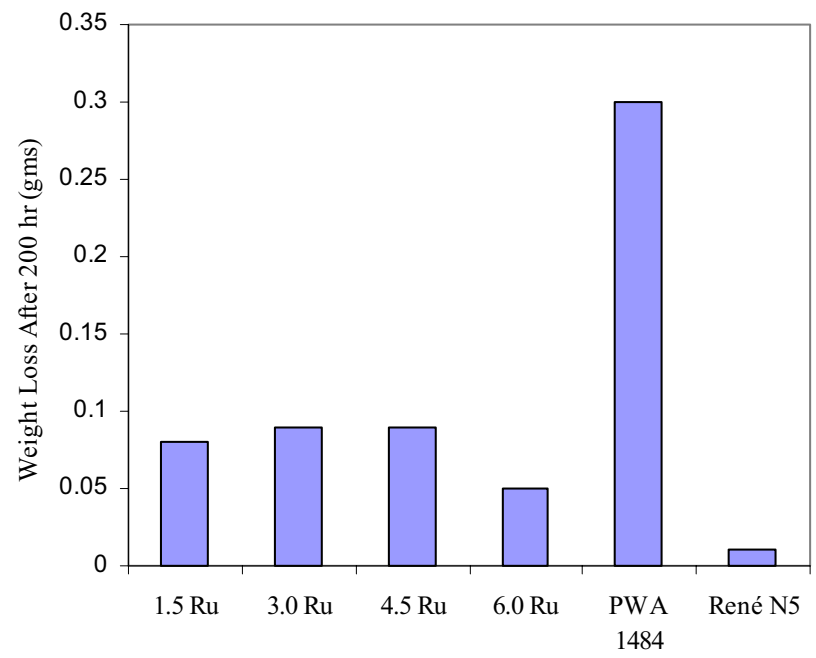

Figure 7. $1177^{\circ} \mathrm{C}$ Mach 1 oxidation test showing no detrimental effect of $\mathrm{Ru}$ on a base alloy's oxidation resistance with all other elements held constant.

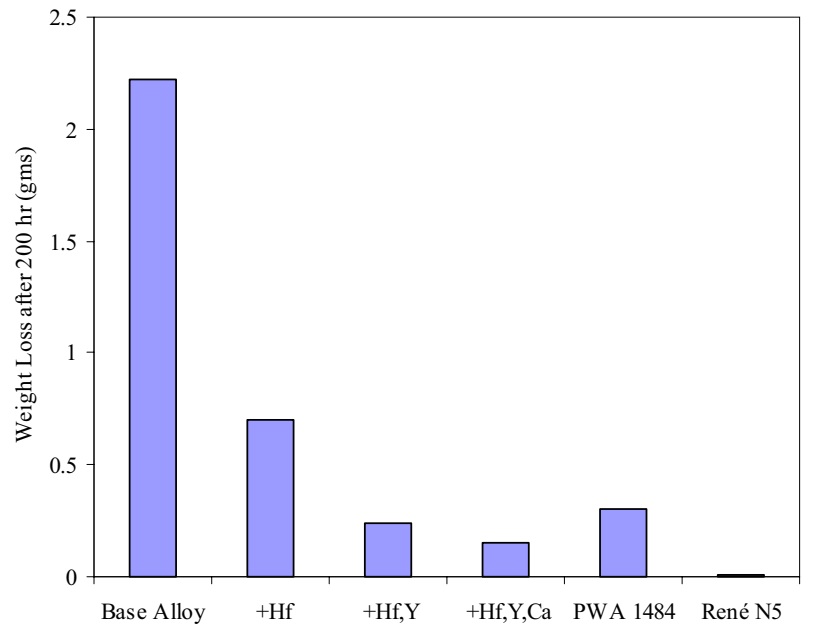

Figure 8. Addition of reactive elements shown to be beneficial to $1177^{\circ} \mathrm{C}$ oxidation resistance.

\section{Compositional Effects on Creep Rupture}

The creep-rupture goal was set at achieving a $42^{\circ} \mathrm{C}$ increase in metal temperature capability over the average of the PWA 1484 and René N5 baselines. To achieve this goal in a stable composition, while achieving a balanced level of other critical properties, was a demanding undertaking. It was obvious from the outset, that a significant increase in alloying content, over the production $2^{\text {nd }}$ and $3^{\text {rd }}$ generation alloys (PWA 1484/René N5 and René N6), would be required to meet this goal.

Alloys with large variations in elemental additions were evaluated to define the alloying content required to achieve the program goal. Initial screening testing conducted at $982^{\circ} \mathrm{C} / 310 \mathrm{MPa}$ (Figure 9) indicated that achieving the 320 hour life goal would require at least 24 weight percent of the refractory elements (Mo + $\mathrm{W}+\mathrm{Ta}+\mathrm{Re}$ ). Many of the alloys with total refractory contents beyond 22 wt.\%, however, were observed to form TCP instability during creep rupture testing. Even higher TCP concentrations formed after long-time exposures at $1093^{\circ} \mathrm{C}$. As shown in Figure 9, moderate to heavy TCP precipitation (solid triangles) reduced creep life below the expected trend line. Reducing the $\mathrm{Cr}$ level (open diamonds) below 3 wt.\% improved the stability of these alloys, but this was still insufficient for reaching the EPM life and stability requirements.

These initial screening tests indicated that a new alloying approach would be necessary to meet the $+42^{\circ} \mathrm{C}$ goal in a stable alloy. $\mathrm{Ru}$ additions were found to be highly effective in meeting this goal without debiting microstructural stability. Ru additions up to $4.5 \%$ were evaluated at $982^{\circ} \mathrm{C} / 310 \mathrm{MPa}$ in several series of base compositions containing 12.5 and $20 \% \mathrm{Co}$, as shown in Figure 10. These trials showed that creep-rupture life increased as $\mathrm{Ru}$ additions were made to the base composition, and that alloys with $3.0-4.5 \% \mathrm{Ru}$, could exceed the program goal of 320 hours. 


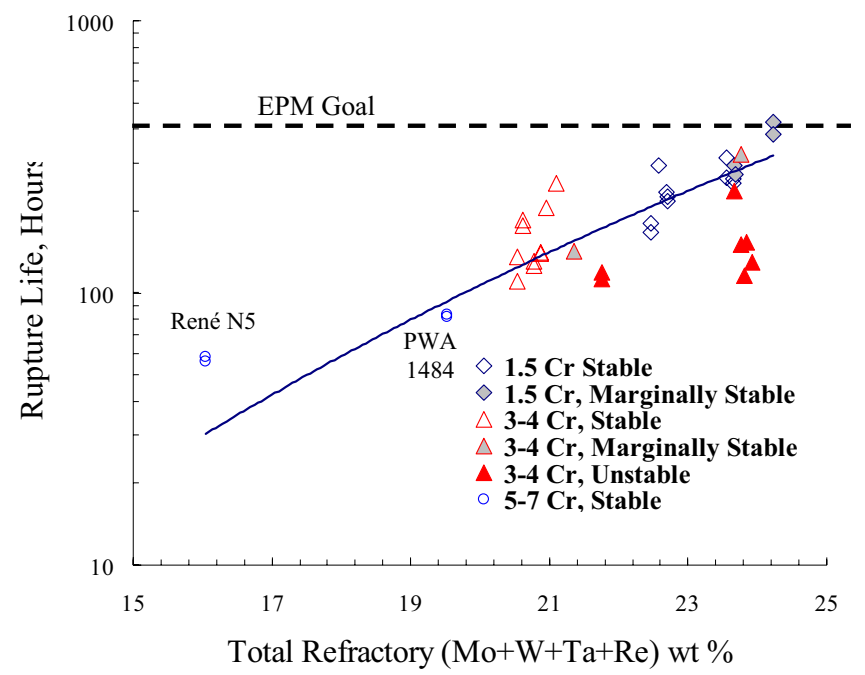

Figure 9. Correlation between refractory element content and rupture life at $982^{\circ} \mathrm{C} / 310 \mathrm{MPa}$ indicates that alloy contents greater than $24 \mathrm{wt}$ \% were required to meet the EPM program goal. Line is drawn through stable alloy data points.

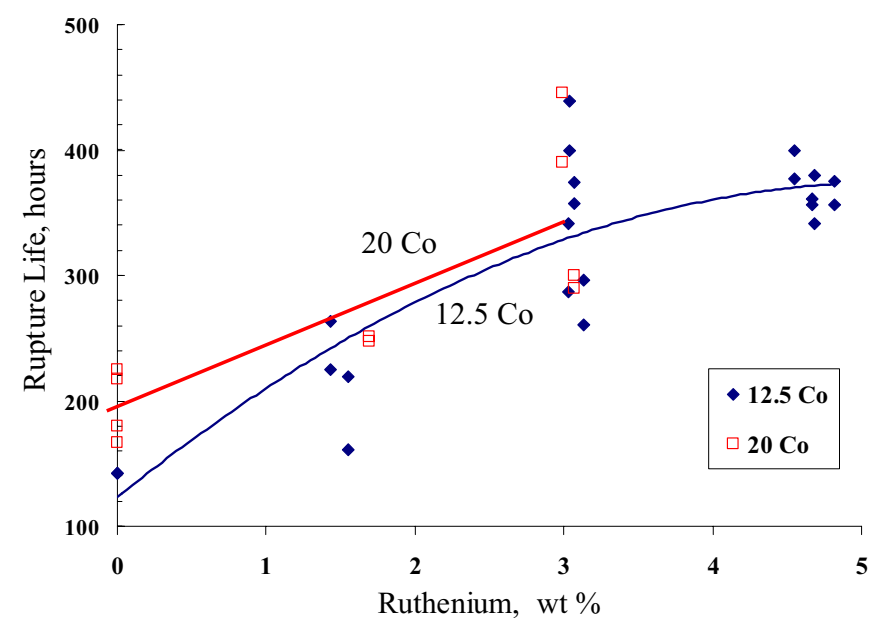

Figure 10. Creep testing at $982^{\circ} \mathrm{C} / 310 \mathrm{MPa}$ shows that rupture life increases with ruthenium additions.

Longer-time creep-rupture testing conducted at $982^{\circ} \mathrm{C} / 248 \mathrm{MPa}$ in a series of alloys with $\mathrm{Ru}$ varying from 1.5 to $6 \%$ (12.5 or $20 \%$ Co) is shown in Figure 11. While Ru had a slightly positive effect on long-time rupture life, Co had a very significant effect.

Additional testing indicated that Co also had a significant influence on creep-rupture behavior at elevated temperature $\left(1093^{\circ} \mathrm{C}\right)$. A series of alloys tested at $1093^{\circ} \mathrm{C} / 152 \mathrm{MPa}$ with cobalt varying from 12.5 to $20 \%$ (Figure 12) indicated that high levels of Co additions reduced creep-rupture life. This trend was the opposite of that observed at $982^{\circ} \mathrm{C}$ (Figure 11). It is believed that one reason the $1093^{\circ} \mathrm{C}$ rupture life was reduced as Co was increased was because Co depresses the $\gamma^{\prime}$ solvus. Differential Thermal Analysis testing revealed that increasing the Co content from $5 \mathrm{wt} . \%$ to $20 \mathrm{wt} . \%$ reduced the $\gamma$ ' solvus by approximately

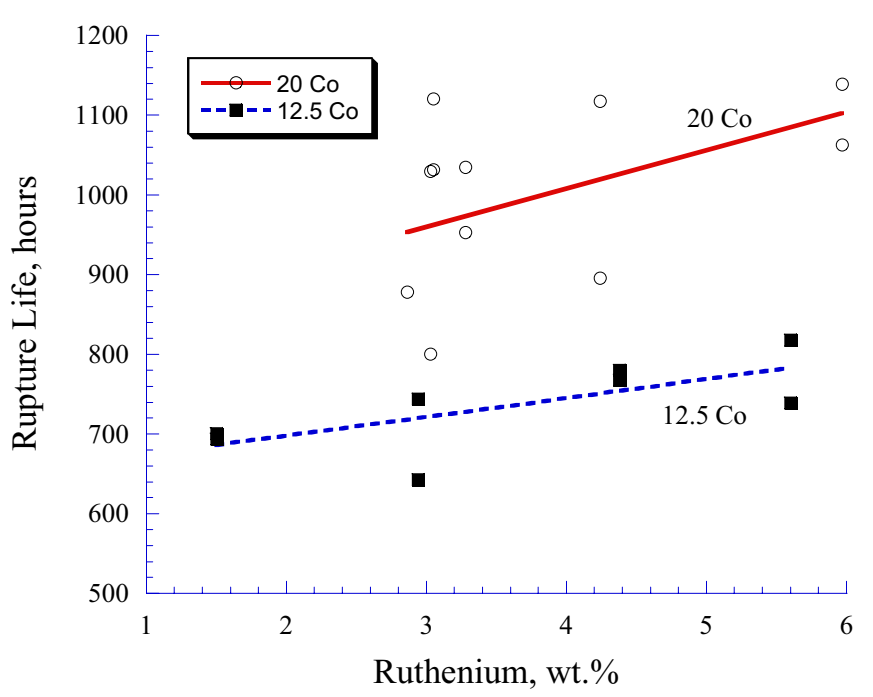

Figure 11. Long-time creep testing at $982^{\circ} \mathrm{C} / 248 \mathrm{MPa}$ shows that high Co levels significantly improved rupture life.

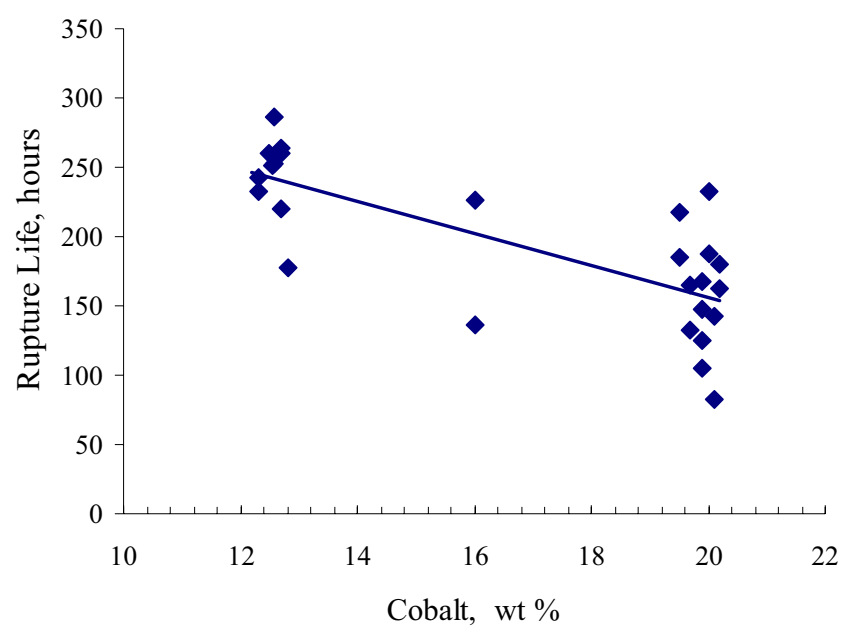

Figure 12. Rupture life at $1093^{\circ} \mathrm{C} / 152 \mathrm{MPa}$ was observed to be inversely related to cobalt content.

$50^{\circ} \mathrm{C}$. Reducing the $\gamma^{\prime}$ solvus would likely lead to faster particle coarsening rates at the higher test temperatures which would reduce alloy creep resistance.

A final screening condition $\left(927^{\circ} \mathrm{C} / 310 \mathrm{MPa}\right)$ was selected, to be more representative of the bulk creep condition in the HSCT mission. This condition was used to define the optimum combination of $\mathrm{Ru}$ and Co content for the EPM alloy. Evaluation of a series of developmental alloys with variations in $\mathrm{Ru}$ ( 3 and $4.5 \%$ ) and Co (12.5 to $25 \%$ ) was conducted, and the results are illustrated in Figure 13. This figure shows that the optimum long-time behavior at $927^{\circ} \mathrm{C}$ could be attained in alloys containing $3 \% \mathrm{Ru}$ with 12.5 to $16 \% \mathrm{Co}$. Alloys with higher $\mathrm{Ru}$ and $\mathrm{Co}$ contents, did not behave as well at $927^{\circ} \mathrm{C}$ in long-time testing and were dropped from further consideration. From the extensive creep-rupture screening testing conducted between 927 to $1093^{\circ} \mathrm{C}$, it was determined that optimized behavior, over the range 
of temperatures of interest, could best be obtained in alloys containing $3 \% \mathrm{Ru}$ and moderate levels of Co (12.5 to $16 \%$ ).

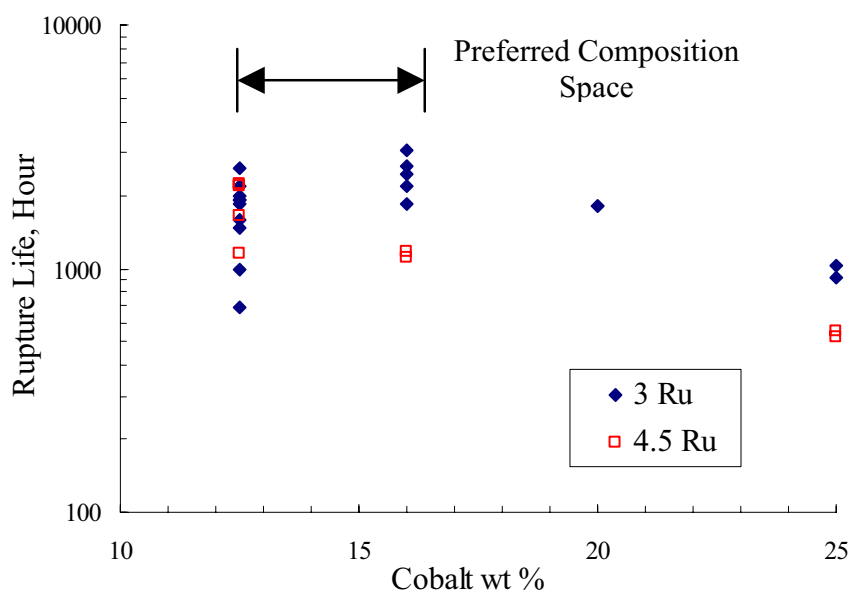

Figure 13. $927^{\circ} \mathrm{C} / 310 \mathrm{MPa}$ testing shows that rupture life decreases in alloys with higher Co $(>16.5 \%)$ and/or higher $\mathrm{Ru}$ $(>3 \%)$ contents.

\section{Alloy Composition and Properties}

Following the composition development phase, three alloys were chosen for producing scale-up heats and additional testing and evaluation. As a result of its excellent performance in various screening tests, EPM-102 was selected as the alloy with the best balance of mechanical properties, environmental resistance and microstructural stability. This alloy became the baseline for a series of heats to further optimize composition and to help define a compositional specification range. In these four optimization heats, small variations of Co (14-17 wt.\%) and Al (5.45-5.7 wt.\%) were evaluated as shown in Table II. From these four alloys, a final composition was defined as shown below in Table III. The density of alloy EPM-102 is $9.20 \mathrm{~g} / \mathrm{cm}^{3}$.

Table II. Co and Al Levels in EPM-102 Optimization Heats (wt.\%)

\begin{tabular}{|c|c|c|}
\hline Alloy & $\mathrm{Al}$ & $\mathrm{Co}$ \\
\hline EPM-102 A & 5.45 & 16.0 \\
\hline EPM-102 C & 5.6 & 17.0 \\
\hline EPM-102 C+ & 5.8 & 17.0 \\
\hline EPM-102 D+ & 5.7 & 14.0 \\
\hline
\end{tabular}

Table III. Composition of EPM-102 (wt.\%)

\begin{tabular}{|c|c|c|c|c|c|c|c|c|c|}
\hline $\mathrm{Cr}$ & $\mathrm{Al}$ & $\mathrm{Ta}$ & $\mathrm{W}$ & $\mathrm{Mo}$ & $\mathrm{Re}$ & $\mathrm{Ru}$ & $\mathrm{Co}$ & $\mathrm{C}$ & $\mathrm{Hf}$ \\
\hline 2.0 & 5.55 & 8.25 & 6.0 & 2.0 & 5.95 & 3.0 & 16.5 & 0.03 & 0.15 \\
\hline
\end{tabular}

Also contains $40 \mathrm{ppm} \mathrm{B}$ and $100 \mathrm{ppm} \mathrm{Y}$
The following sections will describe some of the behavior and properties of EPM-102 and the four alloy optimization heats used to select the final alloy composition specification ranges.

\section{Microstructural Stability of EPM-102}

Long-time furnace exposures and creep-rupture testing demonstrated that EPM-102 has satisfactory long-term microstructural stability with respect to TCP phase formation. The program goal was to design an alloy capable of long time service at intermediate temperatures, such as $982^{\circ} \mathrm{C}$. Under these conditions, EPM-102 shows minimal TCP phase formation which does not affect long-time properties. At higher temperatures, moderate TCP precipitation occurs that slightly degrades longtime properties, similar to other $3^{\text {rd }}$ and $4^{\text {th }}$ generation single crystal superalloys.

EPM-102 does not form internal cellular colonies in the dendrite cores that can significantly degrade creep rupture properties. However, SRZ does develop beneath PtAl and MCrAlY coatings. Figure 14 shows the effectiveness of SRZ mitigation treatments used in reducing or eliminating SRZ in the four optimization heats. Stress relief heat treatments and/or carburization treatments were conducted on turbine blade sections followed by PtAl coating and $1093^{\circ} \mathrm{C} / 400 \mathrm{hr}$ exposures. Based on this work, it was determined that the presence of SRZ can be controlled by the proper combination of coating parameters, stress relief heat treatments and carburization if necessary. After the conclusion of the EPM program, additional creep-rupture testing and microstructural analyses were performed on EPM-102 by NASA Glenn under the Ultra Efficient Engine Technology program [8].

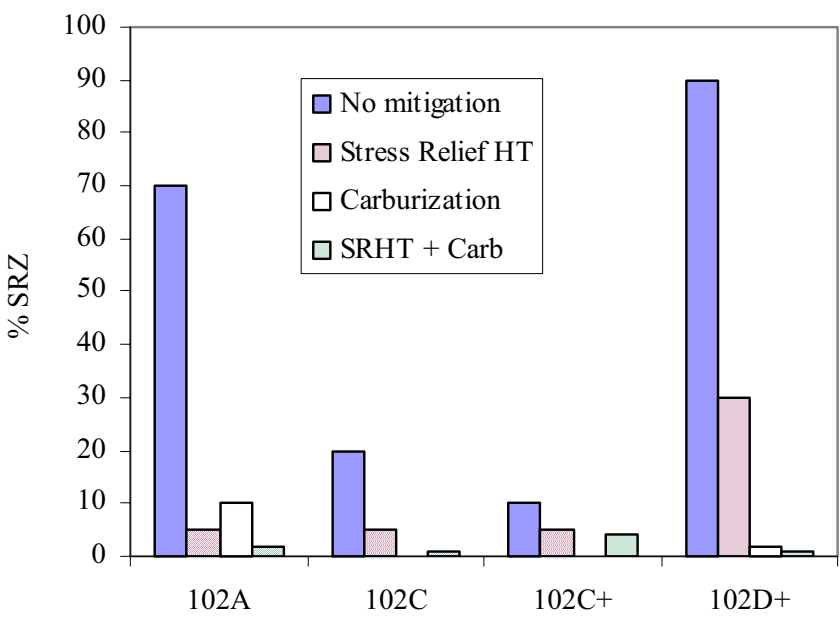

Figure 14. Formation of SRZ under PtAl coating of turbine blade sections of the optimization alloys after exposure at $1093^{\circ} \mathrm{C}$ for 400 hours. If no bar appears, no SRZ was seen. 


\section{Environmental Resistance of EPM-102}

The environmental resistance of EPM-102 was evaluated using a battery of uncoated and coated hot corrosion and oxidation tests. Hot corrosion evaluation of bare specimens was conducted at 815$900^{\circ} \mathrm{C}$ using a cyclic Type I hot corrosion test, as shown in Figure 15. This shows that EPM-102 has slightly worse corrosion resistance than René N5, PWA 1484 and B1900H. Considering the low $\mathrm{Cr}$ content of the alloy, these results are not surprising. A more severe test was conducted with PtAl coated specimens at $927^{\circ} \mathrm{C}$ with 5 ppm sea salt. The specimens lasted nearly 3000 hours, which is considered very good and adequate to avoid typical Type I corrosive attack in engine service operation.

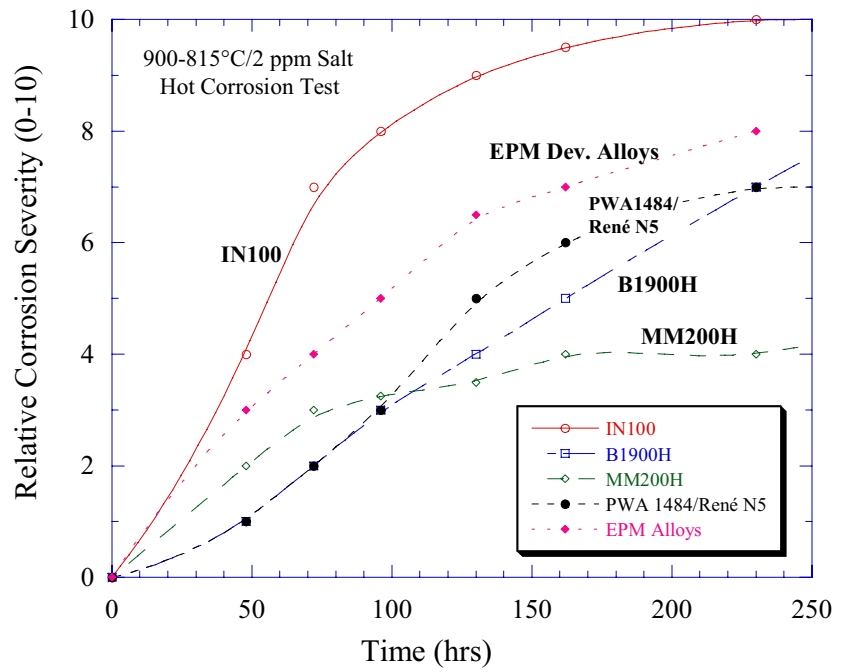

Figure 15. Cyclic hot corrosion resistance of scale-up EPM alloys compared to other superalloys. Test was continuously cycled from $815^{\circ} \mathrm{C}$ to $900^{\circ} \mathrm{C}$ with 2 ppm sea salt.

The $1177^{\circ} \mathrm{C}$ oxidation resistance of uncoated EPM-102 is shown in Figure 16. The program goal was equivalent oxidation resistance to PWA 1484. However, Figure 16 shows that uncoated EPM-102 has slightly lower oxidation resistance than uncoated PWA 1484. Adding a coating significantly improved the oxidation resistance, and the PtAl coated alloy behaved similarly to PWA 1484.

\section{Creep Rupture Properties of EPM-102}

The EPM-102 base alloy was characterized over a wide range of temperature and stress conditions. A Larson-Miller plot of the creep-rupture data generated between 871 and $1149^{\circ} \mathrm{C}$ is contained in Figure 17. In addition, this figure shows the data on the four optimization heats. As shown in this figure, the EPM102 base alloy maintains a significant advantage over the program baseline alloys at all temperature/stress conditions tested, with the biggest improvement evident around $300 \mathrm{MPa}$.

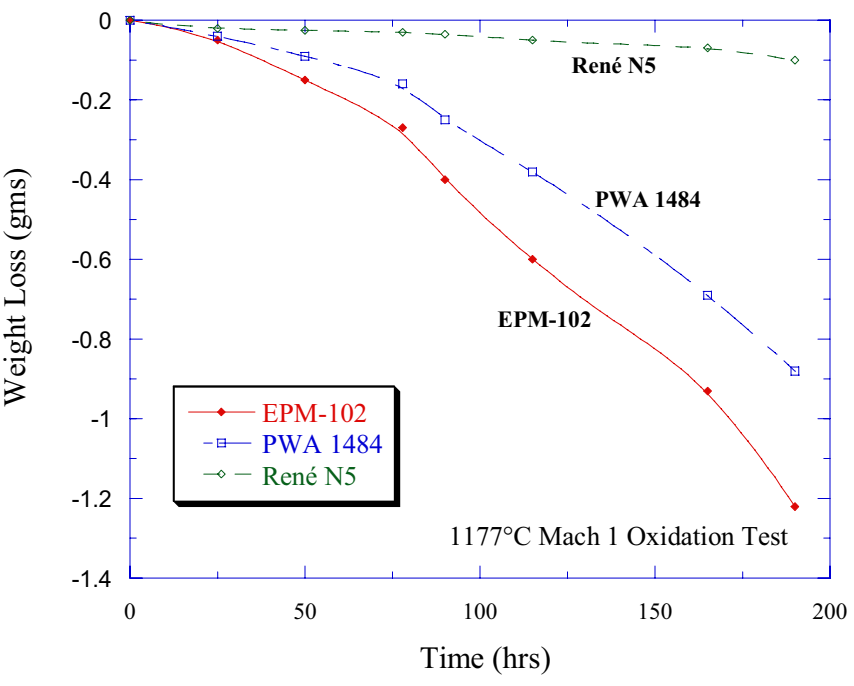

Figure 16. Testing at $1177^{\circ} \mathrm{C}$ shows the oxidation resistance of uncoated EPM-102 is only slightly worse than that of the uncoated baseline alloy PWA 1484.

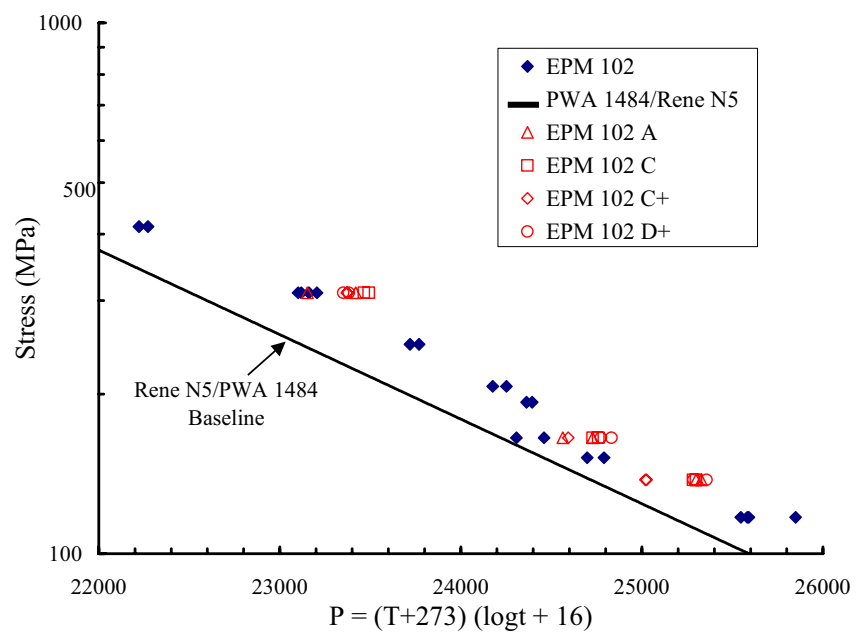

Figure 17. Larson-Miller comparison of creep-rupture life shows significant advantage for the base EPM-102 alloy and the optimization heats over $2^{\text {nd }}$ generation alloy baseline.

Figure 18 shows the $982^{\circ} \mathrm{C}$ rupture behavior of the four heats, and Figure 19 shows their $1093^{\circ} \mathrm{C}$ rupture behavior. Figure 18 shows that the optimization heats approached or exceeded the program goal. While the optimization heats had higher strengths than the base EPM-102 alloy, the more heavily alloyed heats exhibited unacceptable levels of TCP phase formation after exposures at 982 to $1093^{\circ} \mathrm{C}$. Additionally, the lower Co heats formed higher amounts of SRZ under the PtAl coatings after exposures at 982 or $1093^{\circ} \mathrm{C}$. 
PtAl coated testing of EPM-102 was conducted at 927 to $1093^{\circ} \mathrm{C}$ (Figure 20). The coating produced, at most, a minimal debit in creep-rupture life, attributable to small amounts of SRZ which formed beneath the coating during test. In general, the effect of SRZ on creep rupture properties is simply to reduce the effective specimen cross-section thickness. Thus, the debit due to SRZ is a function of temperature, time and the propensity for the alloy/coating system to form SRZ.

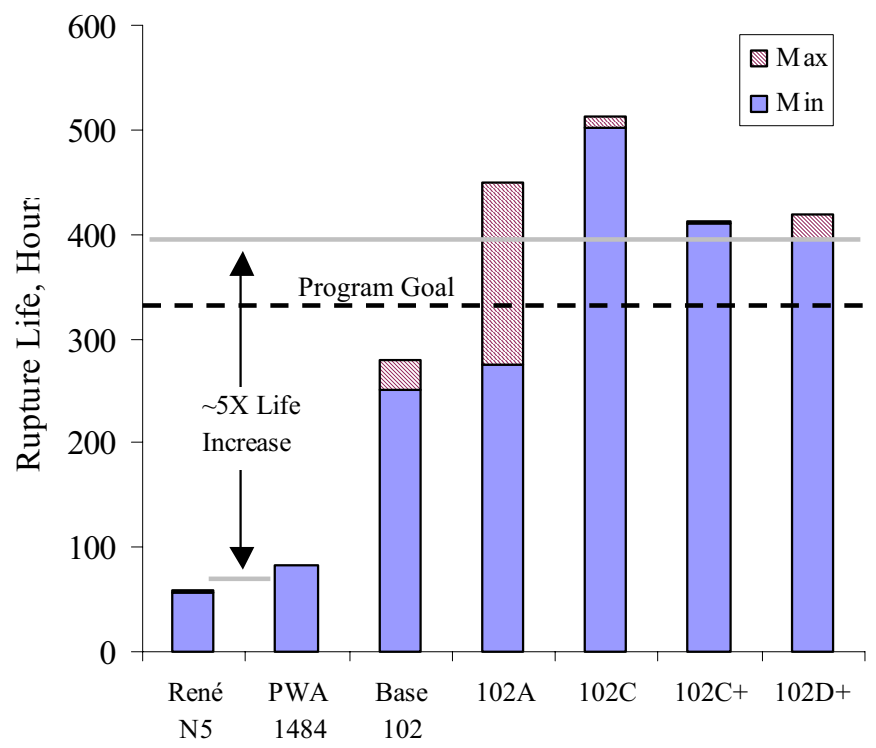

Figure 18. Creep-rupture testing at $982^{\circ} \mathrm{C} / 310 \mathrm{MPa}$ shows large increase in rupture life for the base EPM-102 alloy and the optimization heats over baseline $2^{\text {nd }}$ generation alloys.

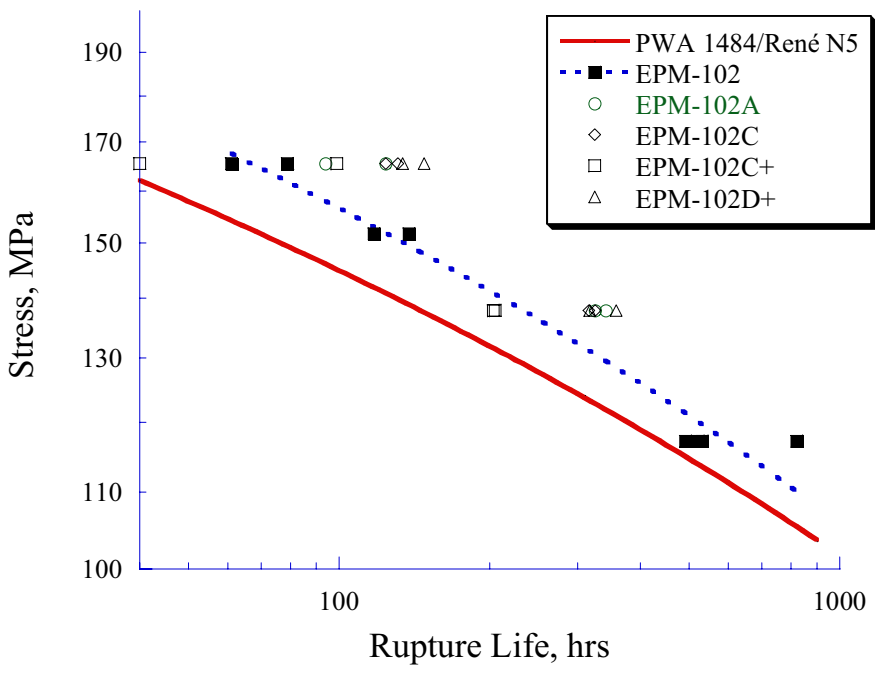

Figure 19. $1093^{\circ} \mathrm{C}$ creep-rupture testing shows small life improvement for the EPM-102 optimization heats over the base EPM-102 alloy and a slight advantage over $2^{\text {nd }}$ generation alloys.

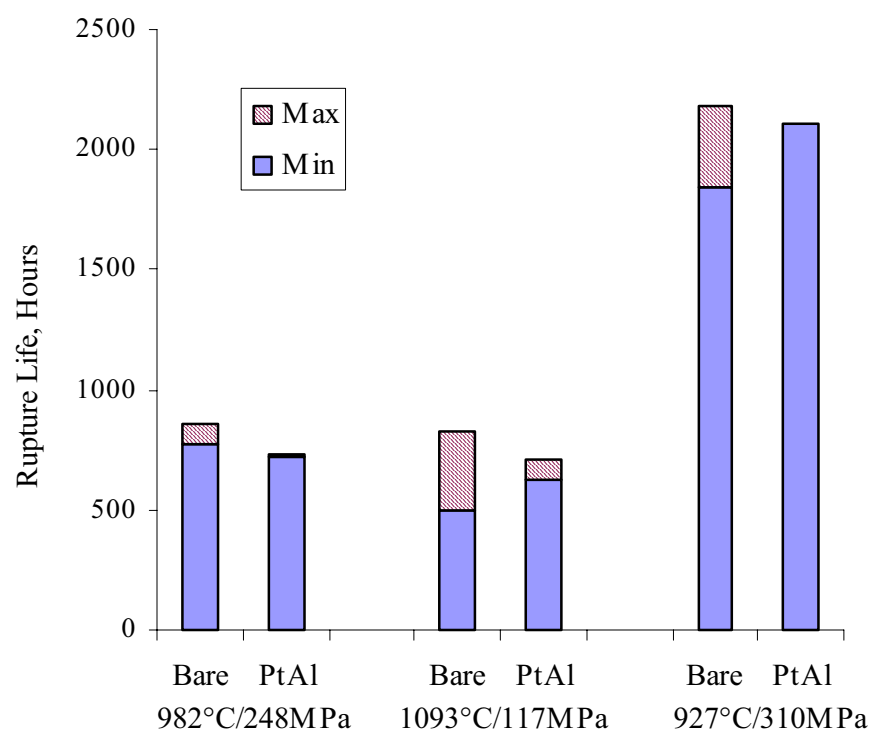

Figure 20. Creep-rupture testing of PtAl coated EPM-102 between 927 and $1093^{\circ} \mathrm{C}$ shows only minor decreases in rupture life vs. uncoated material.

\section{$\underline{\text { Tensile and Fatigue Properties of EPM-102 }}$}

Tensile data was generated on EPM-102 between 649 and $1093^{\circ} \mathrm{C}$ (Figure 21). As shown in this figure, the ultimate tensile strength of EPM-102 is slightly higher than PWA 1484, although the yield strength is slightly below the baseline alloy. High cycle fatigue testing of EPM-102 was conducted at 649 and $982^{\circ} \mathrm{C}$. An example of this behavior is shown in Figure 22 . At $982^{\circ} \mathrm{C}$, EPM102 is significantly stronger than both René N5 and René N6.

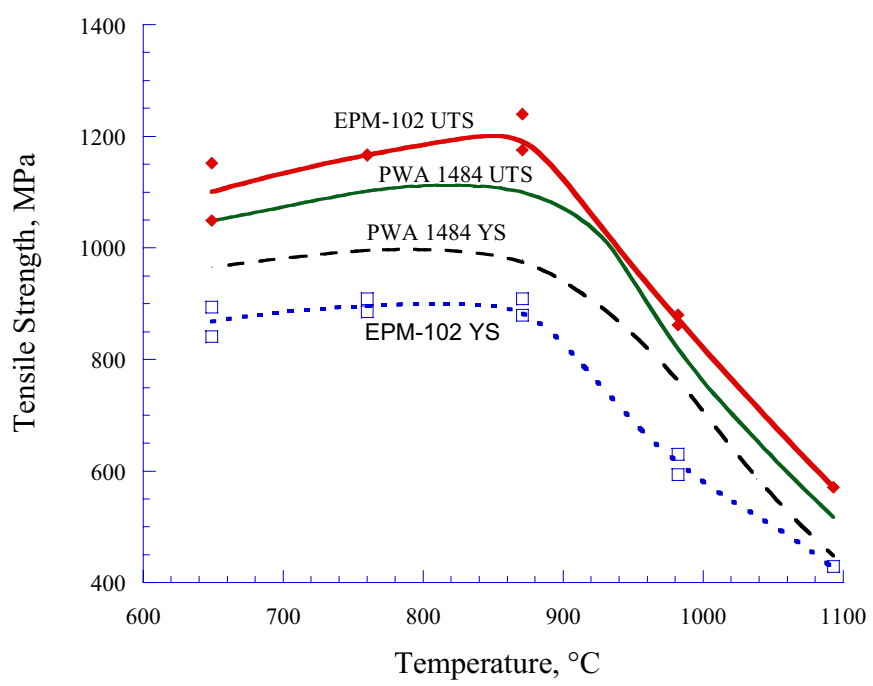

Figure 21. EPM-102 shows improved UTS and a small decrease in yield strength vs. PWA 1484 in tensile testing between 649 and $1093^{\circ} \mathrm{C}$. 


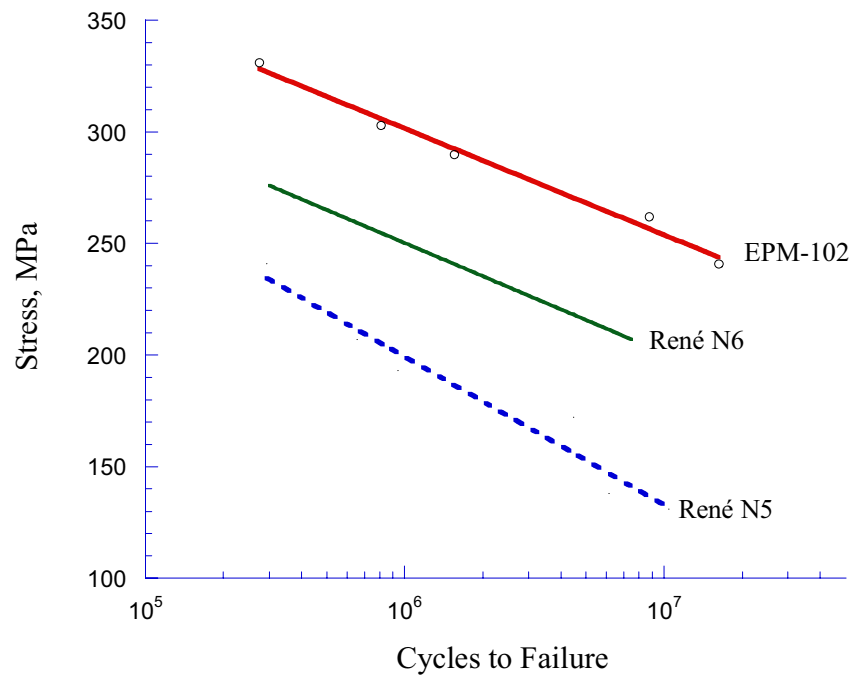

Figure 22. High cycle fatigue testing of EPM-102 at $982^{\circ} \mathrm{C}(\mathrm{R}=0)$ shows improvement over René N5 and René N6.

Strain controlled thermal-mechanical fatigue testing was conducted with a maximum temperature of $1038^{\circ} \mathrm{C}$ (Figure 23) in an out-of-phase cycle, on PtAl-coated specimens. This testing indicated that PtAl-coated EPM-102 provided almost a $2 \mathrm{X}$ advantage in fatigue life over aluminide coated PWA 1484. This advantage is partially derived from the alloy's superior high temperature creep capability.

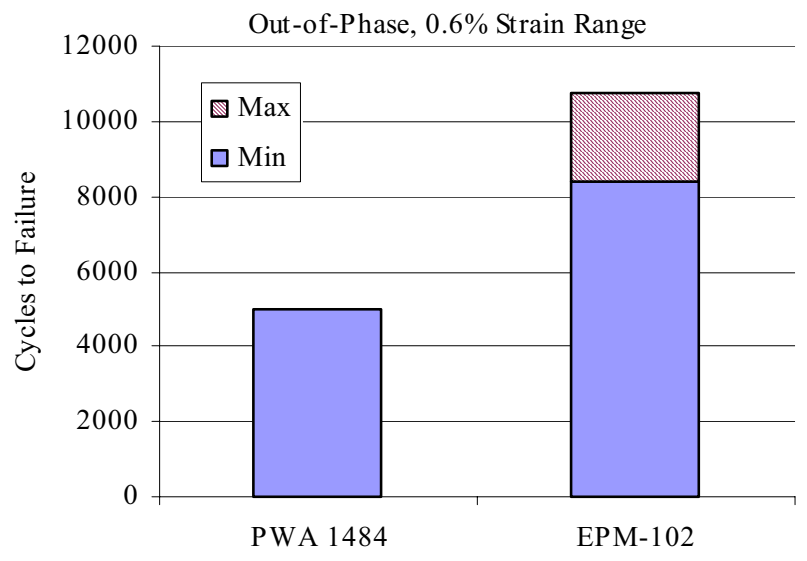

Figure 23. Thermal-mechanical fatigue testing of PtAl-coated EPM-102 with a maximum temperature of $1038^{\circ} \mathrm{C}$ shows significant advantage over PtAl-coated PWA 1484.

\section{Castability and Manufacturability}

Several different high-pressure turbine airfoils, including the F110-129, CF6-80E, PW2037 and PW4098, were successfully cast at Howmet Whitehall Castings and PCC Airfoils. Figure 24 shows a fully machined CF6-80E high pressure turbine (HPT) blade and an as-cast PW4098 HPT blade. The casting trials showed that EPM-102 casting yields and grain structure were similar to other $2^{\text {nd }}$ and $3^{\text {rd }}$ generation single crystal superalloys.
In addition, complex, four-walled HPT blade castings were produced from an alloy similar to EPM-102 with no alloy related issues. Limited manufacturing trials did not reveal any grinding or hole drilling issues using production processes.

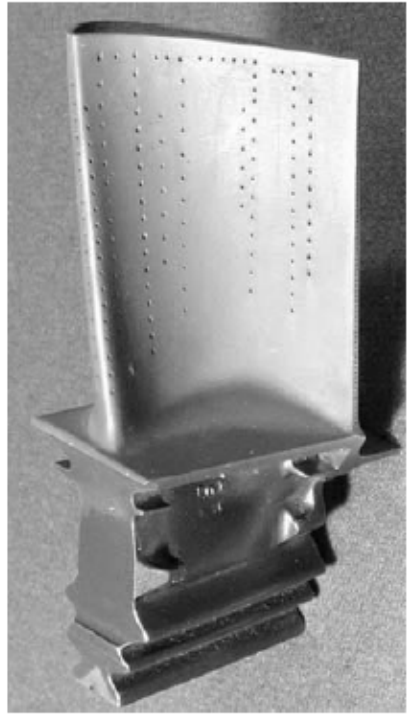

(a)

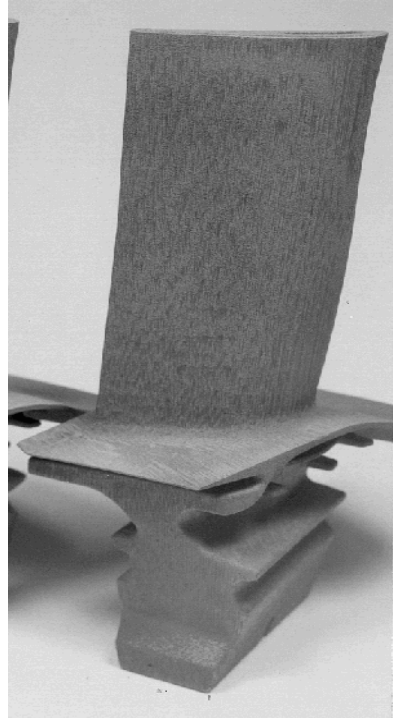

(b)
Figure 24. (a) Fully machined casting of a CF6-80E high pressure turbine (HPT) blade and (b) an as-cast PW 4098 HPT blade.

\section{$\underline{\text { Scale-up Activities }}$}

The EPM-102 alloy was further developed and characterized at both GEAE and P\&W after the conclusion of the EPM program. A significant property database has been created and alloy specifications created. The alloy, known as MX4 at GEAE and PWA 1497 at P\&W, has been engine tested in various advanced engines and is a candidate alloy for turbine airfoils in the Joint Strike Fighter.

\section{Summary and Conclusions}

- To achieve a balance of improved creep rupture strength and microstructural stability, it was necessary to focus development efforts on alloys with lower chromium levels and higher cobalt and rhenium levels than previous alloys, as well as to include a new alloying element, ruthenium.

- Cobalt was found to improve the resistance to TCP formation and reduced the formation of SRZ beneath PtAl coatings. However, the effect of Co on creep-rupture was not straightforward. Cobalt improved long-time rupture properties at moderate temperatures, but Co was also found to lower the $\gamma$ ' solvus and degrade high temperature properties. Thus, an intermediate level of approximately $16 \mathrm{wt} . \%$ provided the best balance of properties. 
- Ruthenium caused "reverse partitioning" such that many of the refractory elements partitioned more strongly to the $\gamma$ ' phase as ruthenium levels were increased. This could be one reason why $\mathrm{Ru}$ improved the microstructural stability and allowed for more refractory elements to be added to improve high temperature strength.

- Environmental resistance of the alloys evaluated was slightly worse than the $2^{\text {nd }}$ generation single crystal superalloys due to lower $\mathrm{Cr}$ and higher refractory element contents. Coated properties were improved and acceptable.

- SRZ instability occurred under PtAl and MCrAlY coatings, however the application of stress relief heat treatments and/or carburization treatments prior to coating application reduced SRZ occurrence to acceptable levels.

- EPM-102 was chosen as the final alloy composition. This alloy has a good balance of strength and microstructural stability and is amenable to current production processes. The alloy has improved creep rupture and fatigue strength compared to the baseline $2^{\text {nd }}$ generation single crystal superalloys. The most significant benefits occur at intermediate temperatures (925$\left.1050^{\circ} \mathrm{C}\right)$.

- The alloy is currently a candidate for advanced engine applications at both GE Aircraft Engines and Pratt \& Whitney.

\section{Acknowledgements}

The authors would like to thank the team of Bob Draper and Ajay Misra at NASA, Ben Bartlett at P\&W and Norm Lindblad and Andy Johnson at GEAE for their guidance and leadership throughout the HSCT program. This was a complex, multi-year, alloy development program and due to space limitations, this paper was not able to report on much of the excellent work conducted. This included phase extraction studies by Dr. Robert Dreshfield at NASA, creep rupture mechanism analysis by Dr. Robert Field at Los Alamos and heat treat effects and SRZ mitigation by Dr. Rebecca MacKay at NASA. Finally, the GEAE authors would like to thank Earl Ross and Gary McCabe for their contributions.

\section{References}

1. W.S. Walston, J.C. Schaeffer and W.H. Murphy, "A New Type of Microstructural Instability in Superalloys - SRZ", Superalloys 1996, ed. R.D.. Kissinger, et al, (Warrendale, PA: TMS, 1996), 9-18.

2. A. Cetel and D.N. Duhl, U.S. Patent 6,007,645, "Advanced High Strength, Highly Oxidation Resistant Single Crystal Superalloy Composition Having Low Cr Content”, 1999.

3. K. O'Hara, W.S. Walston, E.W. Ross and R. Darolia, U.S. Patent 5,482,789, "Nickel Base Superalloy and Article", 1996.

4. P. Caron, "High $\gamma$ ' Solvus New Generation Nickel-based Superalloys for Single Crystal Turbine Blade Applications", Superalloys 2000, ed. T.M. Pollock, et al, (Warrendale, PA: TMS, 1996), 737-746.
5. J.X. Zhang, et al, "Interfacial Dislocation Networks Strengthening a Fourth-Generation Single-Crystal TMS-138 Superalloy" Metallurgical and Materials Transactions A, 33A, (2002), 3741-3746.

6. P. Caron, "French Developments of Superalloys for Gas Turbine Disks and Blades", Advanced Materials and Processes for Gas Turbines", (Warrendale, PA: TMS, 2002), 17-28.

7. R. L. Dreshfield and K. J. Thomas, "Analyses of Elemental Partitioning in Advanced Nickel-Base Superalloy Single Crystals," NASA Technical Memorandum, HSR059, June 1998.

8. R. A. MacKay, et al., "Assessment of Creep Capability of HSR-EPM Turbine Airfoil Alloys,” NASA Technical Memorandum, UEET001, February, 2001. 